\title{
ANTONIO GÓMEZ ROBLEDO: LECTOR DE ARISTÓTELES
}

HÉCTOR ZAGAL ARREguíN

UNIVERSIDAD PANAMERICANA

No es lo mismo ser un especialista en Aristóteles (un aristotelian scholar, dirían los anglosajones) que un filósofo aristotélico. No es lo mismo estudiar la filosofía de Aristóteles que filosofar al estilo de Aristóteles. Para el aristotelian scholar, el Estagirita es un interesante objeto de estudio. Para el segundo, la filosofía de Aristóteles es - al menos parcialmente- verdadera.

¿Era Antonio Gómez Robledo un aristotelian scholar o era un aristotélico? Suele señalarse a Gómez Robledo, prima facie, como un representante del aristotelismo y de la escolástica en México. Sin embargo, tal adjetivación adolece de un defecto: la identificación entre "aristotelismo" y "escolástica".

En el presente escrito hablaré someramente de los dos estilos de estudiar a Aristóteles, y a partir de esa distinción, aventuraré el sentido en que Antonio Gómez Robledo fue un aristotélico.

\section{La vigencia de Aristóteles}

El aristotelismo como estilo de filosofar ha estado vinculado tradicionalmente a la escolástica y, por tanto, ha tenido siempre un dejo de cristianismo. El aristotelismo se asocia ordinariamente a la teología católica. Seminarios y universidades católicas fueron los típicos lugares donde se venía cultivando esta especie de escolástica aristotélica. Al fin y al cabo, el dogma católico está enunciado en terminología de claro corte aristotélico.

Con mayor o menor suerte, este aristotelismo ha permanecido vigente, sorteando los embates del empirismo inglés, del racionalismo continental y finalmente del positivismo francés y del marxismo. No obstante, tal vigencia es muy relativa, pues se debió sobre todo a factores externos a la sistemática escolástica-aristotélica. Me refiero, en concreto, al papel que el catolicismo ha desempeñado para mantener vigente la escolástica. Ésta es, grosso modo, la historia de Aristóteles del siglo XVII al siglo XIX.

Sin embargo, a finales del siglo XIX Franz Brentano "redescubre" a Aristóteles; no como un diccionario filosófico para la teología, sino como un pensador capaz de aportar soluciones a los planteamientos del idealismo 
alemán y del positivismo francés. Brentano retoma el concepto de intencionalidad y el concepto de teleología. Con la noción aristotélica de finalidad, Brentano intentó superar el mecanicismo. A su vez, Husserl intentó escapar del cogito cartesiano con el concepto de intencionalidad, recibido de Brentano. La figura de Brentano es clave en la resurrección de un Aristóteles menos anclado a la teología y más capaz de dialogar con Hegel y con la filosofía de la ciencia moderna.

A partir de las investigaciones de Brentano, Aristóteles fue reivindicado paulatinamente en la filosofía continental y poco a poco fue admitido en la palestra donde disputaban fenomenólogos y marxistas. Los primeros vieron en la noción aristotélica del conocimiento un punto de apoyo (conocer es un acto perfecto que no es susceptible de ser explicado por el psicologismo). Los segundos vieron en el Estagirita un preludio del materialismo científico (así, el célebre Curso de filosofía de Politzer se refiere a Aristóteles como un "materialista vergonzante").

Pero el impulso más decidido al aristotelismo provino del reconocimiento de la vagamente llamada "filosofía analítica". Cuando los analíticos levantaron el interdicto de "sin sentido" que pesaba sobre Aristóteles, el aristotelismo pasó nuevamente a un plano importante. La filosofía analítica había privilegiado la lógica apodíctica y tendía, en sus comienzos, a la axiomática. Frege, Russell y Hilbert son preclaros ejemplos de esta tendencia. Pero en la medida que la lógica de la inferencia natural fue tomando carta de ciudadanía, la riqueza de la lógica aristotélica fue descubriéndose. Los trabajos de Nicholas Rescher, Stephen Toulmin y Paul Lorenzen sobre lógica dialógica fueron decisivos en este punto (la lógica "tópica"). Más recientemente los trabajos de Perelmann, Walton y Woods mostraron la importancia de la retórica en la teoría de la argumentación. Aristóteles apareció así como un lógico "integral", pues lo mismo había una retórica aristotélica que una apododíctica o una lógica del diálogo.

Esta rehabilitación analítica de la lógica aristotélica corrió parejas con una creciente simpatía por su metafísica. Elizabeth Anscombe y Peter Geach son los representantes más conspicuos de tal actitud, seguidos, más discretamente en su simpatía, por figuras como Wiggins o S. Schoemaker.

Sin embargo, la reivindicación más espectacular corrió a cargo de Alsdair McIntyre quien, colocado entre una tradición continental y una tradición analítica, se aventura a defender la vigencia y actualidad de la ética aristotélica, ética de virtudes y no de prohibiciones. ${ }^{1}$ After Virtue de McIntyre

1 ¿No podría firmar McIntyre las siguientes líneas?: “Virtud' es para Aristóteles toda excelencia en general, toda potenciación valiosa de una facultad o de un acto; y de esta suerte lo humano desfila ante nosotros en su mejor aspecto, y ostentando, con esa colorida plasticidad tan propia del genio helénico, el sello del valor. Desfila como en un fresco magnífico en el cual tienen tanta viveza, $\tan$ incomparable fuerza expresiva las virtudes o excelencias de la parte irracional del hombre con sus pasiones y apetitos, como las de la parte racional, y una y otra 
marcó un hito en la resurrección de la filosofía de la acción de corte aristotélico.

Sin miedo a hacer un panegírico, me atrevo a decir que Gómez Robledo se adelantó a este renacimiento del aristotelismo. Ciertamente, su obra mantiene una curiosa distancia de la filosofía analítica. Gómez Robledo nunca fue proclive a la literatura anglosajona, si bien siempre reconoció sus méritos. Con todo, este adelantamiento de Gómez Robledo discurre por líneas muy semejantes a las del renacimiento aristotélico anglosajón.

Esta "anticipación" descansa en tres puntos:

1) Un conocimiento erudito y profundo de las fuentes aristotélicas. No es ningún secreto que el aristotelismo escolástico en boga en seminarios y universidades católicos de fines del XIX y primera mitad del XX era -en no pocas ocasiones- un aristotelismo ayuno de fuentes. Se enseñaba a Aristóteles con comentadores secundarios y manuales (y no pocas veces con franco predominio de la manualística sobre los mismos comentaristas). El estudio concienzudo del corpus aristotelicum quedaba reservado para historiadores. Parte del actual "redescubrimiento" de Aristóteles se explica como un auténtico desempolvamiento del corpus.

2) Una preocupación por recuperar la dimensión sapiencial de la filosofía. Por dimensión sapiencial de la filosofía entiendo: a) que la filosofía es conocimiento universal; b) que la filosofía es, en cierto sentido, un saber de salvación y de perfeccionamiento humano.

Universalidad y soteriología ya están claramente presentes en la concepción platónica de la filosofía. Platón concibe la filosofía con una triple función: meditatio mortis (en el Fedón); respuesta a la sofística (e.g., en el Gorgias); arte del bien gobernar (la República). Importantes obras de Gómez Robledo se centran en estos aspectos de la filosofía socrática y platónica.

Pero como buen discípulo de Platón, es decir, como buen aristotélico, Gómez Robledo retoma el concepto de sabiduría purificado de todos los inconvenientes metafísicos platónicos. Se nota en la obra de don Antonio una búsqueda constante de la filosofía como saber con implicaciones vitales. Esta preocupación se palpa lo mismo en la Meditación sobre la justicia ${ }^{2}$ que

cosa en la vida personal y social, hasta alcanzar esa cumbre única en la historia del pensamiento filosófico, que es la descripción de la sabiduría." Gómez Robledo, Ensayo sobre las virtudes intelectuales, FCE, México, 1957, p. 11. Llamo la atención sobre la fecha de publicación.

2 Copio casi al azar un párrafo del ensayo "La justicia en Aristóteles": "Como quiera que sea, y sin introducir en Aristóteles lo que no alcanzó ni a vislumbrar, la justicia y la amistad representan, en su cosmovisión y en el orden práctico, la apertura entitativa de quien, como el hombre, no puede tener su último fin en sí mismo. De esta condición son, por lo demás, todos los otros entes, con la sola excepción del Pensamiento eternamente subsistente 'que se piensa a sí mismo' [... ] Justicia y amistad son así, en las relaciones interhumanas, una etapa dialética en el proceso cósmico de esta sublime teleología. De una y otra percibimos mejor su belleza y trascendencia cuando las contemplamos insertas en el gran poema que es el universo 
en El pensamiento filosófico de Edith Stein o en la acre polémica de El caso Lefebvre. Aunado a un magnífico trabajo de fuentes, Gómez Robledo toma postura en sus libros. Este tomar postura va mucho más allá de la investigación documental, pues la filosofía como sabiduría no es turris eburnea, sino saber práctico. Acaso esta actitud fue objetivada por Gómez Robledo en su trabajo diplomático.

En todo caso, su atención a la ética aristotélica y a la filosofía política de Platón manifiestan el énfasis de Gómez Robledo en la vertiente sapiencial de la filosofia. Las traducciones de la República, de la Ética nicomaquea y de la Ética eudemia -con sus respectivas introducciones-son un locus clasici para entender por qué Gómez Robledo concebía la filosofía como algo más que un estudio teórico.

De particular importancia fue su última obra, la edición de la Ética eudemia, pues en la introducción Gómez Robledo se descara — por así decirloy apuesta a una concepción de la ética como saber práctico. Es decir, sabe ética quien es ético. La tesis no puede ser más aristotélica. Tesis, por otro lado, que se vislumbra en la obra de McIntyre y que caracteriza hoy por hoy la teoría de la acción aristotélica. ${ }^{3}$

3) La noción de hábito y virtud. En 1957, Antonio Gómez Robledo publicó Ensayo sobre las virtudes intelectuales y tres años antes había aparecido su traducción —con una larguísima introducción- de la Ética nicomaquea. En ambas obras, particularmente en la primera, se centra la atención en el tema aristotélico del hábito y de la virtud.

Como he dicho anteriomente, a largo del siglo XIX y parte del XX la ética tiende a reducirse a un mero código, a un conjunto de normas carentes de sentido dinámico por estar enunciadas en términos prohibitivos. Según tal concepción de la ética (presente en algunos manuales neoescolásticos), la función más importante de la ética es prohibitiva. La ética de inspiración aristotélica tenía a cuestas una larga tradición de moralistas (con todo un fardo de casuística interminable) y, además, los cargos lanzados desde la filosofía kantiana (el eudemonismo aristotélico como ética heterónoma y, por tanto, indebida). Tanto la casuística como el formalismo kantiano habían penetrado insensiblemente en la mente de los filósofos morales de inspiración aristotélica (neoescolásticos). Tales influencias hicieron perder a la ética aristotélica su carácter positivo: ser ético no es evitar las acciones malas, sino lograr la excelencia (areté) y plenitud humana.

Otro tanto sucedió en el ámbito del conocimiento teórico. No es ningún secreto que las síntesis medievales del conocimiento (las grandes sumas)

entero, y que 'se forma por sí solo bajo el eterno influjo del pensamiento puro'." Meditación sobre la justicia, FCE, México, 1982, p. 86.

3 Un intento temprano de recuperar el auténtico sentido de la prudencia aristotélica se encuentra en Verdad y método de Gadamer. Un intento más reciente de recuperar la prudencia aristotélica se encuentra en la obra de Enrico Berti. 
entrañaron un riesgo en el que a veces se sucumbió: la memorística y la consecuente "arteriosclerosis" por el énfasis en la sistematización. No pocas veces la filosofía de inspiración aristotélica perdió de vista que la auténtica ciencia no es tanto un conjunto de proposiciones sistemáticamente articuladas, sino un hábito intelectual. Saber una ciencia, en el aristotelismo de buena cepa, no es "saber" una serie de definiciones, sino tener un hábito intelectual (una disposición del entendimiento, una estructura de la inteligencia). Dicho "hábito" permite resolver nuevos problemas, establecer relaciones, integrar nuevas proposiciones; todo ello sobrepasa con mucho una visión de la ciencia como sistema.

Gómez Robledo, en su Ensayo sobre las virtudes intelectuales, se nos presenta ahora como un preclaro antecesor de esta recuperación del concepto de "hábito" como principio de la ética y de la formación intelectual. Basta pensar, por ejemplo, que no es sino hasta 1971 cuando Ando Takatura publica su célebre Aristotle's Theory of Practical Cognition, ${ }^{4}$ en el que se replantea el concepto aristotélico de virtud en un sentido semejante a como años antes lo había hecho Gómez Robledo.

A partir de estos tres puntos, puede decirse que Gómez Robledo tiene una concepción viva del aristotelismo como fuente de inspiración. Un aristotelismo que empalma con algunos acercamientos analíticos y hermenéuticos a Aristóteles en lo que respecta a la teoría de los hábitos y en particular a la prudencia.

\section{La historiografía aristotélica}

Aunque Aristóteles dejó de ser un autor relativamente "vivo" en el siglo XIX, la historiografía aristotélica sí permaneció viva. Basta pensar en Hermann Bonitz, Trendelenburg o en la edición de Commentaria in Aristotelem græca, publicada en Berlín dèsde el siglo pasado.

Este interés de tipo historiográfico recibió un firme impulso con el trabajo de Werner Jaeger e Ingermar Düring. La lectura genético-evolucionista del corpus aristotelicum generó un gran interés y renovó decididamente la historiografía aristotélica. Se escribieron muchos libros y artículos, bien tratando de reconstruir el auténtico corpus, bien negando la autencidad de tal o cual obra aristotélica. En este contexto se sitúan obras como Die Entwicklung der aristotelischen Logik und Rhetorik de F. Solmsen, Die aristotelische Idee der erste Philosopie de Laura Routila o Sophia: The Science Aristotle thought de Chung Hwan Chen.

Este modo de historiar a Aristóteles causó auténtico furor y llevó -amparándose en la filología - a desdoblar a Aristóteles en dos filosófos opuestos

4 Nijhoff, La Haya, 1971. 
e irreconciliables: un joven Aristóteles de vena platónica y más o menos teocentrista, y un Aristóteles viejo, racionalista y ligeramente escéptico. Ética eudemia y Ética nicomaquea fueron enfrentadas como paradigmas de dos posturas filosóficas distintas.

Hoy por hoy, la polémica genético-evolucionista ha perdido vigor en buena medida por las investigaciones de Giovani Reale y Anthony Kenny. Parte de la bibliografía entonces escrita ha perdido interés y tiene un valor muy circunscrito. Gómez Robledo tuvo la capacidad de situar la discusión en su justo contexto. Sus magníficas introducciones a las dos éticas toman en cuenta la postura de Jaeger. No obstante, sin caer en un irenismo sincretista, Gómez Robledo supera el asunto, asumiendo que, en todo caso, la evolución del joven Aristóteles al Aristóteles maduro es una evolución consistente, que no conduce a destazar el corpus en infinidad de fragmentos de textos aleatoriamente unidos por los antiguos.

Esto da a las obras aristotélicas de Gómez Robledo una vigencia de la que carecen ahora libros de otros autores que no hace mucho tiempo fueron best-sellers. Gómez Robledo -como lector de Aristóteles-- supo dar a las teorías de Jaeger su lugar. $\mathrm{Ni}$ las desechó en pro de una lectura anticuada y monolítica del corpus (un Aristóteles sin fisuras y sin evoluciones), ni las sobrevaloró hasta el punto de descalificar a los comentaristas tradicionales.

Tan importante como la historiografía continental de Aristóteles es ahora la historiografía anglosajona (ya me referí a Kenny). La tradición que arranca de David Ross ha dado frutos interesantes. Martha Nussbaum, Richard Sorabji, G.E.R. Owen, Malcolm Schofield, Jonathan Barnes son tan sólo algunos nombres.

Recogiendo la más pura tradición anglosajona, estos últimos autores se acercaron a Aristóteles con una visión más argumentativa que el viejo estilo de Trendelenburg o Bonitz. Han presentado un Aristóteles más "fresco" y mucho menos filológico que los alemanes y franceses (a pesar de que Ross cultivó el comentario filológico).

Gómez Robledo apreció a Kenny, pero echó de menos en los otros aristotelian scholars la visión de conjunto y, sobre todo, el contexto históricocultural al que era tan dado Gómez Robledo. Por ejemplo, en su reciente introducción a la Ética eudemia, no sólo se menciona a Jaeger, Düring y Kenny, se menciona también a San Agustín y a Cicerón, a quienes Gómez Robledo trae a cuento con ocasión del concepto de sabiduría. La sophía eudemia es de raigambre platónica y, por tanto, está en la línea del Hortensius de Cicerón, leído por Agustín de Hipona, quien a su vez difundiría en Occidente un concepto de sabiduría menos racionalista y más vital.

Gómez Robledo gusta de situar a Aristóteles en su contexto: Grecia. De igual manera gusta de relacionar a Aristóteles con sus seguidores (los filósofos romanos, San Agustín, la escolástica, Edith Stein, etc.). Este tratamiento de Aristóteles le da a las obras de Gómez Robledo una textura histórica y 
cultural. Textura que en ocasiones perdemos quienes nos dedicamos a un Aristóteles demasiado argumentativo o metafísico.

Recuerdo que mientras escribía un trabajo sobre la argumentación no científica en Aristóteles, don Antonio me llamó la atención por no incluir en la bibliografía La retórica antigua de Alfonso Reyes. Adujo, entre otras razones, que tratándose de un helenista mexicano (eso y mucho más fue Reyes) no podía yo dejarlo soslayado. Una vez leída La retórica antigua, entendí que mi aproximación a la Retórica de Aristóteles carecía de un necesario marco histórico. La argumentación retórica de Aristóteles es la respuesta concreta a una situación concreta (de hecho, el intento formal de la retórica aristotélica no se entiende plenamente sin la figura de Isócrates).

Este sentido del contexto estaba bien lejos de un historicismo. Sirvan como ejemplo dos pistas bibliográficas que el mismo Gómez Robledo me dio con ocasión de otro trabajo, esta vez sobre la epagogé en Aristóteles. Las dos pistas fueron: Die epagogé bei Aristoteles de Kurt von Fritz y la monumental obra en tres tomos, Die Syllogistik bei Aristoteles de Heinrich Maier. No me resultó fácil conseguir la obra de von Fritz, pues don Antonio ya no tenía consigo el libro. Después de recorrer bibliotecas, terminé pidiendo el libro a la Academia Bávara que había publicado el texto hace años. Debo confesar que me impresionó la soltura con que se refirió a ese texto tan raro como útil para estudiar la inducción aristotélica.

El conocedor de Aristóteles se percatará de que la lectura de libros como los de Maier o von Fritz, junto con un delicado tratamiento de fuentes, una conveniente contextualización cultural y una toma de postura sobre la actualidad de la doctrina del corpus, hacen de Gómez Robledo un original estudioso del Estagirita.

Me atrevería a decir que esto se nota también en su estilo de traducir. Antonio Gómez Robledo - poseedor de una prosa castellana magníficatraducía permitiéndose ciertas paráfrasis. La traducción literal era, según Gómez Robledo, un intento de fidelidad que hacía ininteligible al escritor traducido. La traducción excesivamente literal terminaba siendo tan poco clara para el lector lego como el griego original. Las críticas que algunos hacen a las traducciones griegas y latinas de Gómez Robledo deben, por tanto, tener en cuenta que no se trata de un defecto técnico, sino de una actitud metodolbgica. Actitud que, por otro lado, engarza perfectamente con su acercamiento a Aristóteles.

\section{Aristotelismo mexicano}

Como corolario podría añadirse que Gómez Robledo supo encontrar la influencia de Aristóteles en México. El magisterio filosófico de fray Alonso de la Veracruz es una muestra de ello. Al fin y al cabo, como auténtico humanista, Gómez Robledo aspiraba a encontrar las múltiples relaciones del espíritu 
humano. Lo mismo siguió la pista de Aristóteles en la discípula de Husserl, Edith Stein, que en la escolástica novohispana.

Así, Gómez Robledo fue un buen aristotélico. Su lectura del corpus está hecha con un prisma notablemente platónico (platónico-agustiniano, quizá) y fuertemente tomista. Y escribo "tomista" y no "escolástico" porque Gómez Robledo se adelantó también al rescate contemporáneo de un Tomás de Aquino más auténtico y menos "neoescolástico". 